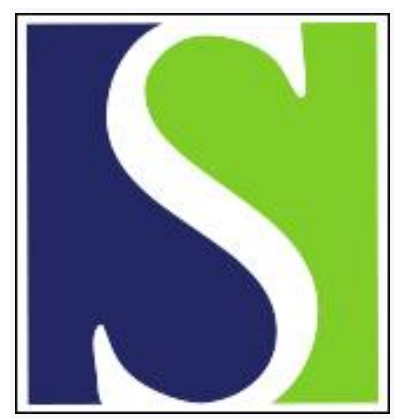

Scand J Work Environ Health 2012;38(4):358-369

https://doi.org/10.5271/sjweh.3256

Published online: 24 Oct 2011, Issue date: 01 Jul 2012

Burned out cognition - cognitive functioning of burnout patients before and after a period with psychological treatment

by Oosterholt BG, Van der Linden D, Maes JHR, Verbraak MJPM, Kompier MAJ

Affiliation: Department of Work and Organizational Psychology, Behavioural Science Institute, Radboud University Nijmegen, PO Box 9104, 6500 HE, Nijmegen, the Netherlands. b.oosterholt@psych.ru.nl

Refers to the following text of the Journal: 2007;33(3):223-232

The following articles refer to this text: 2014;40(6):569-581; 2017;43(4):337-349

Key terms: burnout; chronic stress; cognition; cognitive behavioral therapy; cognitive control; cognitive functioning; cognitive process; executive control; executive function; executive functioning; fatigue; psychological treatment; stress; work stress

This article in PubMed: www.ncbi.nlm.nih.gov/pubmed/22025205 


\title{
Burned out cognition - cognitive functioning of burnout patients before and after a period with psychological treatment
}

\author{
by Bart G Oosterholt, MSc, ${ }^{1,2}$ Dimitri Van der Linden, PhD,1, 3 Joseph HR Maes, PhD, ${ }^{2}$ Marc JPM Verbraak, \\ $P h D, 4,5$ Michiel AJ Kompier, $P h D^{1}$
}

\begin{abstract}
Oosterholt BG, Van der Linden D, Maes JHR, Verbraak MJPM, Kompier MAJ. Burned out cognition - cognitive functioning of burnout patients before and after a period with psychological treatment. Scand J Work Environ Health. 2012;38(4):358-369. doi:10.5271/sjweh.3256
\end{abstract}

\begin{abstract}
Objectives Many employees with burnout report cognitive difficulties. However, the relation between burnout and cognitive functioning has hardly been empirically validated. Moreover, it is unknown whether the putative cognitive deficits in burnout are temporary or permanent. Therefore, the purpose of the study was to answer two related questions: (i) Is burnout associated with self-reported cognitive difficulties and with deficits in a specific and well-defined set of executive functions? (ii) Do these putative self-reported cognitive difficulties and deficits in executive functioning in burnout diminish after a 10 -week period with cognitive behavioral therapy?
\end{abstract}

Methods Sixteen employees with burnout were compared with sixteen matched healthy employees on selfreported cognitive difficulties and tests measuring the basic executive functions, namely, updating, inhibition, and switching, on two test occasions. The interval between the test occasions was ten weeks, during which the burnout individuals received cognitive behavioral therapy.

Results On the first test occasion, and relative to healthy individuals, individuals with burnout reported more cognitive difficulties and showed deficits in the "updating" function. No group differences were found regarding the "inhibition" and "switching" functions, although individuals with burnout generally responded slower than healthy individuals on the latter test. Even though after the ten-week treatment period individuals with burnout revealed positive changes regarding burnout symptoms, general health, and self-reported cognitive difficulties, no evidence was found for improved cognitive test performance.

Conclusions These findings suggest that either (i) burnout leads to permanent cognitive deficits, (ii) subjective burnout complaints reduce faster than deficits in cognitive test performance, or (iii) cognitive deficits are a cause rather than a consequence of burnout.

Key terms chronic stress; cognitive control; cognitive behavioral therapy; cognitive process; executive functioning; executive control; executive function; fatigue; stress; work stress.

Epidemiological studies have shown that a relatively large number of employees experience high and chronic levels of stress at work $(1,2)$. For a relevant proportion of these employees, their stress complaints become so severe that they are no longer able to maintain adequately their job performance or, worse, they drop out of work (2-4). To date, the majority of research on such employees' complaints has been conducted under the label of burnout: a work-related chronic affective state, characterized by emotional exhaustion, depersonalization, and reduced personal accomplishment (5-7). Even though burnout is not included in the most recent version of the Diagnostic and Statistical Manual of Mental Disorders (DSM-IVTR; 8), numerous studies have shown that it is a useful concept in describing the major characteristics of many employees with work-related chronic stress complaints.

Early burnout research mainly focused on its antecedents, its impact on a person's attitudes and health,

1 Department of Work and Organizational Psychology, Behavioural Science Institute, Radboud University, Nijmegen, the Netherlands.

2 Donders Institute for Brain, Cognition and Behaviour, Centre for Cognition, Radboud University, Nijmegen, the Netherlands.

3 Department of Work and Organizational Psychology, Institute of Psychology, Erasmus University, Rotterdam, the Netherlands.

4 HSK Group, Arnhem, the Netherlands.

5 Behavioural Science Institute, Radboud University, Nijmegen, the Netherlands.

Correspondence to: Bart Oosterholt, Department of Work and Organizational Psychology, Behavioural Science Institute, Radboud University Nijmegen, PO Box 9104, 6500 HE, Nijmegen, the Netherlands. [E-mail: b.oosterholt@psych.ru.nl] 
and its organizational consequences (9). Recent studies also indicate that individuals with burnout often complain about impaired cognitive functioning, such as reporting attentional and memory problems (eg, 6). This is not surprising given that burnout may be considered a stress-related syndrome (5), and there is ample evidence that sustained stress can have detrimental effects on neuronal structures involved in cognitive functioning, such as the hippocampus and the prefrontal cortex (eg, 10-12). More specifically, there is substantial literature indicating that the association between stress and impaired cognitive functioning may be mediated by chronically elevated levels of glucocorticoids (eg, cortisol), which in turn may lead to a reduction in total brain weight (13) and, more specifically, to atrophy of the hippocampus $(11,14)$ and the prefrontal cortex $(12)$.

Remarkably, however, the hypothetical relationship between clinical burnout and cognition has hardly been empirically validated using objective measures. To the best of our knowledge, to date there are only seven studies in which this relationship has been examined (15-21). The results of these studies suggest that subjective cognitive complaints of individuals with burnout are linked to actual cognitive deficits, as measured with cognitive neuropsychological tests. The pattern of these deficits seems to indicate that burnout is particularly accompanied by compromised executive functioning, and individuals with burnout have less difficulty with more automatic cognitive processes.

The term executive functioning refers to a set of higher-order cognitive processes that regulate other cognitive sub-processes (22). Importantly, executive functions are widely held to be mediated by a neuronal circuitry that involves prefrontal cortical areas (eg, 23). As opposed to more automatic cognitive processes, executive functions are responsible for the voluntary regulation of thought and action (24). For example, these functions enable an individual to respond appropriately to novel, changing, or complicated tasks or situations (25). The literature describes a wide range of executive functions (eg, 26), including working memory, verbal reasoning, task switching, cognitive flexibility, abstract thinking, inhibition, sequencing, planning, rule acquisition, and problem-solving.

Minor deficits in executive functions can have a devastating impact on a person's private as well as professional life. For example, individuals may be unable to respond adequately in social contexts, structure tasks, or maintain their usual performance. Given the importance of executive functioning, the objective of this study was to add further knowledge to the sparse literature on the relationship between burnout and cognitive functioning. Previous studies addressing this issue focused on a variety of executive functions that were assessed with various cognitive neuropsychological tests. In this study, however, we aimed at examining the relationship between burnout and cognitive functioning more systematically. Specifically, we concentrated on three basic types of executive functions, namely, updating and monitoring of working memory representations ("updating"), inhibition of prepotent responses ("inhibition"), and switching between tasks or mental sets ("switching"). In line with Miyake and colleagues (22), our motive in assessing these specific functions was that there is a relatively large consensus that these are basic executive functions, which can be clearly and precisely described (in contrast to other more higherlevel constructs of executive functioning, such as planning or abstract thinking) and can be operationalized in relatively simple, well-studied, and validated cognitive tasks. Furthermore, these three executive functions are considered to be involved in the performance of other more complex executive functioning tests.

To this end, we compared a group of employees with burnout against a matched healthy control group to assess their performance on a well-chosen set of executive-functioning tests. The burnout group was carefully selected so as to preclude the comorbidity with mood and anxiety disorders. This enabled a relatively pure assessment of the relationship between burnout and cognition. A further characteristic of the individuals in the burnout group was that they received cognitive behavioral therapy (CBT) according to a treatment protocol for burnout, which is commonly used in the Netherlands (27). This therapy was not specifically directed at alleviating cognitive complaints, but rather that these individuals with burnout received a treatment over a period of about ten weeks that gave us the opportunity to establish any possible changes in cognitive performance as a result of the treatment and/or the lapse of time. Specifically, we acquired data concerning burnout symptoms, physical and mental complaints, and both subjective and objective cognitive performance, using a set of standard questionnaires and executive functioning tests prior to and after the treatment period. We expected burnout symptoms and physical and mental complaints to improve in the course of the treatment period, but the question of interest was whether or not cognitive performance (subjective and/or objective) would also show any improvements. Such improvements are to be expected only if the prolonged stress, held to underlie the burnout symptoms, did not result in any permanent brain damage and/or when cognitive deficits are a consequence rather than a cause of burnout.

In sum, the purpose of this study was to answer two related questions: (i) Is burnout associated with self-reported cognitive difficulties and with deficits in a specific and well-defined set of executive functions? (ii) Do these possible self-reported cognitive difficulties and deficits in executive functioning in burnout diminish after a 10 -week period with CBT? 


\section{Methods}

\section{Participants}

In total 32 employees, 16 diagnosed with burnout and 16 matched healthy controls, participated in this study. The participants in the burnout group were selected on the basis of their diagnosis, established by professional clinical psychologists from HSK Group. HSK Group is a major mental healthcare organization in the Netherlands, with several offices across the country. The participants with burnout, who were referred by general practitioners, were recruited from three HSK Group offices where they were diagnosed and received CBT for their burnout. Although burnout is not classified in the DSM-IV-TR, in the Netherlands a burnout diagnosis is commonly based on the DSM-IV-TR criteria for diagnosing an undifferentiated somatoform disorder with the addition of work-related causes. This procedure was also used for the burnout diagnosis in our study. Even though the symptomatology of burnout overlaps with several other psychological disorders such as depression and anxiety disorders, it has been suggested that burnout is a distinct construct (28). Therefore, an exclusion criterion for participation was current fulfillment of DSM-IV-TR criteria for any other axis I or II disorder. At the onset of the study, 7 of the 16 burnout participants were on sick leave due to their burnout, 5 continued working but worked fewer hours than before their burnout diagnoses, and 4 were still working the same number of hours as before the diagnoses. At the time of the second testing session, three individuals were on sick leave, nine worked less, and four worked the same number of hours compared to before their burnout. On both the first and the second testing session, two individuals in the burnout group were treated with psychotropic drugs.

Control group participants were recruited in the same part of the Netherlands as burnout group participants, from several different companies. The 16 healthy controls who participated in our study were matched to the burnout group according to the demographic characteristics of gender, age, level of education, and contractual working hours per week (based on the working hours of individuals with burnout before their diagnosis) (see table 1 for detailed information). None of these participants received treatment for psychiatric disorders. In addition, participants in the control group were screened by means of the Dutch translation (29) of the MiniInternational Neuropsychiatric Interview 5.0.0 (30) and were excluded if they fulfilled the criteria of any DSMIV-TR axis I disorder assessed with this interview. One participant in the control group used a psychotropic drug on the first and second testing sessions. At the time of both measurements, all participants in this group were actively employed. In the burnout as well as the control group, the majority of the participants were working in the education, health, government, or industrial sectors.

\section{Measures: self-reports}

Utrechtse Burnout Scale. The severity of burnout symptoms was measured with the Utrechtse Burnout Scale (31), which is the Dutch adaptation of the widely used Maslach Burnout Inventory (32). We used the version for general professions (Utrechtse Burnout Scale-A), which contains 15 questions to be answered on a 7-point Likert scale ( $0=$ "never", $6=$ "every day"). The questionnaire consists of three subscales: emotional exhaustion, depersonalization, and personal accomplishment. Sample items are, respectively, "I feel mentally exhausted by my job", "I doubt about the usefulness of my job", and "I know well how to solve problems in my job". The individuals with burnout who were on sick leave during the first and/or second testing session were instructed to fill in the items of the Utrechtse Burnout Scale questionnaire according to how they would feel if they were working at that moment. For practical research purposes, Brenninkmeijer \& Van Yperen (33) proposed that individuals can be classified high in burnout when they have a high score $(>2.19)$ on emotional exhaustion and a high score $(>1.99)$ on depersonalization or a low score on personal accomplishment $(<3.67)$. Measured with Cronbach's alpha, the internal consistencies of the subscales were respectively, $0.88,0.69$, and 0.83 .

Symptom Checklist-90-Revised. We used the Dutch adaptation (34) of the Symptom Checklist-90-Revised (SCL-90-R), a multi-dimensional questionnaire that assesses physical and mental complaints (35). The SCL-90-R is commonly applied by psychiatrics and psychologists to monitor psychiatric and psychological treatment. The 90 items in this questionnaire describe different physical and psychological complaints, for which one has to indicate the extent to which he/she encounters them on a 5-point Likert scale $(1=$ "not at all", 5="extremely"). The Dutch SCL-90-R consists of 8 subscales, which measure the primary symptom dimensions of anxiety (10 items), agoraphobia ( 7 items), depression (16 items), somatization (12 items), insufficiency (9 items), sensitivity (18 items), hostility (6 items), and sleeplessness (3 items), and an additional subscale (9 items). The sum of the scores on the subscales is referred to as the psychoneuroticism score, which is the equivalent of the Global Severity Index (English version). The mean psychoneuroticism score of the Dutch population is 118 (34). Cronbach's alpha of this questionnaire was 0.95 .

Cognitive Failure Questionnaire. A Dutch translation of the Cognitive Failure Questionnaire (36) was used to assess 
Table 1. Sample characteristics. [SD=standard deviation.]

\begin{tabular}{|c|c|c|c|c|c|c|c|c|c|c|c|}
\hline & \multicolumn{5}{|c|}{ Burnout group } & \multicolumn{5}{|c|}{ Control group } & \multirow[t]{2}{*}{$P$-value } \\
\hline & Mean & SD & Range & N & $\%$ & Mean & SD & Range & $\mathrm{N}$ & $\%$ & \\
\hline Age (years) a & 40.21 & 10.23 & $27-57$ & & & 41.16 & 11.03 & $26-57$ & & & $0.80^{b}$ \\
\hline Level of education c & 3.69 & 0.60 & $2-4$ & & & 3.50 & 0.63 & 2-4 & & & $0.49^{d}$ \\
\hline Work hours/weeke & 36.00 & 4.32 & $24-40$ & & & 34.59 & 8.24 & $16-48$ & & & $0.55^{b}$ \\
\hline \multicolumn{12}{|l|}{ Gender } \\
\hline Men & & & & 8 & 50 & & & & 8 & 50 & $1.00^{d}$ \\
\hline Women & & & & 8 & 50 & & & & 8 & 50 & $1.00^{d}$ \\
\hline
\end{tabular}

the participants' self-reported cognitive functioning. This questionnaire consists of 25 items, which assess cognitive failures in daily life. The items can be answered on a 5-point Likert scale ( $0=$ "never", $4=$ "very often"). Sample items are "Do you read something and find you have not been thinking about it and must read it again?", "Do you find yourself suddenly wondering whether you've used a word correctly?", and "Do you find you forget appointments?" Research has shown that individuals with impaired executive functions exhibit many of the cognitive failures in daily life as assessed with the Cognitive Failure Questionnaire (37). Cronbach's alpha was 0.92.

\section{Measures: cognitive tests}

To examine the relationship between burnout and executive functioning, we focused on the aforementioned three types of functions: updating, inhibition, and switching. These functions were measured by three well-validated tests, each tapping specifically into one of the three target functions.

2-Back Task. To assess updating, we used a 2-Back Task (38), consisting of 197 letters, displayed one-by-one in the centre of the screen. Participants were instructed to push a button on a button-box when the present letter was similar to the letter that had appeared two stimuli previously (target rate was $32.5 \%$ ). Stimuli consisted of the letters b, d, g, p, t, and v, which were displayed quasi-randomly in both capital and small letters (for a correct response no distinction was made between capital and small letters). Stimulus duration was fixed at $450 \mathrm{~ms}$ with an inter-stimulus interval of $750 \mathrm{~ms}$. The test lasted approximately four minutes. Performance was assessed by the mean number of correct responses.

Sustained-Attention-to-Response Test. The SustainedAttention-to-Response Test (SART) (37) was used to measure inhibition. The present version consisted of dig- its, ranging from $1-9$, that were sequentially displayed in a quasi-random order in the centre of the screen. Participants were instructed to push a button on a buttonbox each time a digit appeared on the screen, except when the digit was a " 3 ", which occurred in $11.1 \%$ of the cases. A total of 225 digits, each with a duration of $250 \mathrm{~ms}$, was presented. The interval between digits was set at $850 \mathrm{~ms}$. Completion of the test took about four minutes. The main performance measure in the SART is the number of inhibition errors, in which a participant presses the button when a " 3 " appears on the screen.

Matching Task. Switching was assessed with the Matching Task (39), a variant of the task-switching paradigm, as originally developed by Jersild (40). In this test, four different geometric figures (a circle, a hexagon, a square, and a triangle), displayed in the colors blue, green, red, or yellow were used as stimuli. On each trial, a colored reference figure was shown in the upper half of the screen, and four colored match figures were displayed in the lower half of the screen. Participants were instructed to match the reference figure to one of the match figures according to shape or color. The colorshape combination of the figures was shown randomly with two restrictions. First, the four match figures were not allowed to have the same shape or color. Second, the reference and the match figures were not allowed to match in both shape and color. The type of task, matching according to shape or form, was randomly chosen and indicated by a cue that was displayed for $1000 \mathrm{~ms}$. Matching was performed by pushing one of the four buttons on the keyboard which corresponded to one of the four match figures in the lower half of the screen. The response-stimulus interval was set at $700 \mathrm{~ms}$. The test consisted of 31 task runs, each consisting of on average six trials (range: $4-8$ trials). During one single task run, no task switch - that is matching according to color or shape - occurred. Half of all task runs consisted of "switch" runs, in which the type of task differed from 
the previous run. The other half consisted of "repetition" runs, in which the type of task was identical to the previous run. The duration of the test was approximately six minutes. Besides general reaction time, the most important dependent variable in this task is the switch cost: the difference in reaction time on the first trial between switch and repetition runs. Error and no-response trials and trials that directly followed such trials were not included in the analysis. Just like the first entire task run, a task run, which followed a task run in which all trials were errors, was excluded from the analysis (for more detailed information about this task, see 39).

\section{Procedure}

All participants were tested twice. Testing of the burnout group occurred before or after the participant's regular appointment with the psychologist in a quiet room at one of the three offices of the mental healthcare organization. For half of the participants with burnout $(\mathrm{N}=8)$, the first test session was conducted before their treatment started. Four participants had already received one therapy session before they were tested the first time, and four participants had already received two therapy sessions. However, all participants with burnout were tested for the first time within 3 weeks after they were diagnosed with burnout. After the first test session, all burnout individuals were treated during a period of approximately 10 weeks (range: 8-17), wherein they received an average of 11 sessions (range: 7-13) of CBT before they were tested a second time. A therapy session lasted 45 minutes. Treatment was provided by professional clinical psychologists according to a treatment protocol for burnout (27) that is commonly used in the Netherlands. Basic components of this treatment are reduction of complaints, cognitive therapy, and relapse prevention. If necessary, additional therapy modules can be chosen. After this period of psychological treatment (treatment had not been finished for any of the participants), participants were tested a second time. This follow-up measurement was scheduled after ten therapy sessions because the mental healthcare organization regularly evaluates its patients' progress after this number of sessions. Similar to the participants in the burnout group, approximately 10 weeks (range: $8-14$ ) after the first test session, the participants in the control group were tested a second time. The healthy controls were tested at their homes or at the university in a quiet setting.

During each test session, participants completed the different questionnaires and then the three cognitive tests. The latter were provided in a counterbalanced order across participants, but for each participant, the order of the tests was similar in the first and second session. All tests were computerized and conducted on a laptop with a 15 -inch screen. Participants were placed approximately $50 \mathrm{~cm}$ in front of the computer screen. The tests were introduced with written instructions on the screen as well as verbally explained by the experimenter. Participants were instructed to respond as quickly and accurately as they could by pushing the required button with their dominant hand. The participant had a short practice session (approximately 30 seconds) before initiation of each test. In advance, participants were informed by letter that the purpose of the study was to investigate the effects of mood on cognition. Participants were asked not to consume any caffeine on the examination day. The Ethical Committee of the Faculty of Social Sciences at the Radboud University Nijmegen in the Netherlands approved the study.

\section{Statistical analysis}

Statistical analyses were performed using SPSS for Microsoft Windows, version 17.0 (SPSS, Inc, Chicago, IL, USA). Inspection of the data revealed that the outcome measures were approximately normally distributed. An alpha level of 0.05 was used for all statistical analyses, and the results were based on two-tailed tests.

To examine whether burnout is associated with self-reported cognitive difficulties and with deficits in executive functioning, all outcome measures on the first test session, except performance on the Matching Task, were analyzed with a univariate analysis of variance (ANOVA). Performance on the Matching Task was statistically evaluated using a $2 \times 2$ mixed design ANOVA with "run type" (switch versus repetition) as withinsubject factor and "group" (burnout versus control) as between-subject factor.

To examine whether possible self-reported cognitive difficulties and deficits in executive functioning during burnout diminish after a 10 -week period with CBT, we used a repeated measures ANOVA. All outcome measures, except performance on the Matching Task, were tested with a $2 \times 2$ ANOVA, with "group" (burnout versus control) as between-subject factor and "time" (first versus second test session) as within-subject factor. The Matching Task performance was tested with a $2 \times 2$ $\times 2$ mixed repeated measures ANOVA, with "run type" (switch versus repetition) and "time" (first versus second test session) as within-subject factors, and "group" (burnout versus control) as between-subject factor. Where necessary, interaction effects were further qualified by independent samples and paired samples t-tests.

\section{Results}

The results are presented in two main sections. First, results are reported that are relevant for determining whether burnout is associated with self-reported cogni- 
tive difficulties and with deficits in executive functioning (in table 2 referred to as research question 1). Second, results are presented that are relevant for determining whether possible self-reported cognitive difficulties and deficits in executive functioning in burnout diminish after a 10 -week period with CBT (in table 2 referred to as research question 2).

\section{Burnout and cognitive functioning}

Self-reports. Analysis of the Utrechtse Burnout Scale revealed that the burnout group had significantly higher scores on the emotional exhaustion and depersonalization subscales and a marginally significantly lower score on the personal accomplishment subscale than the healthy control group (for statistics, see table 2). Analysis of the SCL-90-R and the Cognitive Failure Questionnaire scores revealed that, compared to healthy individuals, individuals with burnout reported significantly more physical and mental complaints and more cognitive failures.

Cognitive tests. Compared to the control group, the burnout group had a significantly lower number of correct responses in the 2-Back Task, but the groups did not differ in number of inhibition errors in the SART (see table 2 for statistics). Analysis of the reaction times of the first trials of each task run of the Matching Task revealed significant main effects of run type (switch versus repetition) and group but no significant interaction effect. As usually found in these kinds of tasks (41), the main effect of run type was due to the average reaction time of both groups being significantly faster after a task repetition than after a task switch. However, the main group effect implied that, independent of run type, individuals in the burnout group reacted significantly slower than individuals in the control group. The absence of a run type $\times$ group interaction reflected the absence of a significant difference in switch cost between the two groups.

\section{Changes after a 10-week period with cognitive behavioral therapy}

Self-reports. Analysis of the Utrechtse Burnout Scale emotional exhaustion subscale revealed significant main effects of group and time and a significant group $\times$ time interaction (see table 2). Follow-up independent t-tests showed that before and after the 10 -week period, individuals in the burnout group reported significantly more emotional exhaustion than individuals in the control group $[\mathrm{t}(1,30)=-5.95, \mathrm{P}=0.00 ; \mathrm{t}(1,30)=-3.84, \mathrm{P}=0.00$, respectively]. However, follow-up paired t-tests revealed that individuals with burnout showed a relatively strong and significant decrease in emotional exhaustion from the first to second measurement $[\mathrm{t}(1,15)=2.64, \mathrm{P}=0.02]$, whereas the control group did not differ significantly over time $[t(1,15)=0.00, P=1]$. Analysis of the depersonalization subscale revealed a significant main effect of group indicating that, overall, the burnout group scored significantly higher on depersonalization than the control group. There was, however, neither a significant main effect of time nor significant group $\times$ time interaction, implying respectively, that the average depersonalization score of both groups did not differ over time, and the difference between individuals with burnout and healthy individuals on this measure did not significantly differ on the first compared to the second measurement. For the personal accomplishment subscale, neither a significant main effects of group and time nor significant group $\times$ time interaction were found.

Analysis of the SCL-90-R scores revealed significant main effects of group and time and a significant group $\times$ time interaction. Subsequent t-tests indicated that on the first as well as second testing session, individuals in the burnout group experienced significantly more physical and mental complaints compared to individuals in the healthy control group $[t(1,30)=-5.15, \mathrm{P}=0.00 ; t(1,29)=$ $-2.79, \mathrm{P}=0.01$, respectively]. Follow-up paired t-tests revealed that both the burnout and control group differed significantly over time with regard to their complaints $[t(1,14)=3.29, \mathrm{P}=0.01 ; t(1,15)=2.21, \mathrm{P}=0.04$, respec tively]. However, individuals with burnout showed a stronger decrease in complaints than healthy individuals.

Regarding the Cognitive Failure Questionnaire scores, there were significant main effects of group and time as well as a significant group $\times$ time interaction. Subsequent tests revealed that, on both time points, the burnout group reported significantly more cognitive failures than the control group $[t(1,30)=-3.70, \mathrm{P}=0.00$; $t(1,30)=-2.12, \mathrm{P}=0.04$ for the first and second testing session, respectively]. However, paired t-tests showed that individuals with burnout reported significantly fewer cognitive failures on the second compared to the first measurement $[t(1,15)=3.69, \mathrm{P}=0.00]$, which was not the case for the healthy controls $[t(1,15)=1.09, \mathrm{P}=0.29]$.

In sum, after a 10-week period with CBT, individuals in the burnout group were less emotionally exhausted, had less physical and mental complaints, and reported less cognitive failures than before this period. However, their level of emotional exhaustion and health complaints - though reduced - remained higher than those of the control group, just as they, in addition to depersonalization, remained high compared to norm scores.

Cognitive tests. Analysis of the number of correct responses in the 2-Back Task revealed significant main effects of group and time, but there was no significant interaction (for statistics see table 2). The main effects indicated that, overall, the burnout group performed worse than the control group, and that the average 
Table 2. Means and standard deviations (SD) of the outcome measures and the results of the statistical analyses. [CFQ=Cognitive Failure Questionnaire; EE=emotional exhaustion; $\mathrm{D}=$ depersonalization; $\mathrm{G}=$ group; $\mathrm{PA}=$ personal accomplishment; $\mathrm{Rt}=$ run type; $\mathrm{SART}=\mathrm{Sustained}$ Attention to Response Test; SCL-90-R=Symptom Checklist-90-revised; T=time; UBOS=Utrechtse Burnout Scale.]

\begin{tabular}{|c|c|c|c|c|c|c|c|c|c|c|c|c|c|c|c|c|c|c|}
\hline & \multicolumn{4}{|c|}{$\begin{array}{l}\text { First testing } \\
\text { session }\end{array}$} & \multicolumn{4}{|c|}{$\begin{array}{l}\text { Second testing } \\
\text { session }\end{array}$} & \multicolumn{5}{|c|}{$\begin{array}{l}\text { Results for research } \\
\text { question } 1\end{array}$} & \multicolumn{5}{|c|}{$\begin{array}{c}\text { Results for research } \\
\text { question } 2\end{array}$} \\
\hline & \multicolumn{2}{|c|}{$\begin{array}{l}\text { Burnout } \\
\text { group }\end{array}$} & \multicolumn{2}{|c|}{$\begin{array}{l}\text { Control } \\
\text { group }\end{array}$} & \multicolumn{2}{|c|}{$\begin{array}{l}\text { Burnout } \\
\text { group }\end{array}$} & \multicolumn{2}{|c|}{$\begin{array}{l}\text { Control } \\
\text { group }\end{array}$} & \multirow[t]{2}{*}{ Source } & \multirow[t]{2}{*}{$d f$} & \multirow[t]{2}{*}{$\begin{array}{c}\text { F- } \\
\text { value }\end{array}$} & \multirow[t]{2}{*}{$\begin{array}{l}\mathrm{P}- \\
\text { value }\end{array}$} & \multirow[t]{2}{*}{$\eta^{2}$} & \multirow[t]{2}{*}{ Source } & \multirow[t]{2}{*}{$\mathrm{df}$} & \multirow[t]{2}{*}{$\begin{array}{c}\mathrm{F}- \\
\text { value }\end{array}$} & \multirow[t]{2}{*}{$\begin{array}{c}\mathrm{P}- \\
\text { value }\end{array}$} & \multirow[t]{2}{*}{$\eta^{2}$} \\
\hline & $M$ & SD & $M$ & SD & $M$ & SD & $\mathrm{M}$ & $\mathrm{SD}$ & & & & & & & & & & \\
\hline \multirow[t]{2}{*}{$\begin{array}{l}\text { UBOS } \\
\text { EE sub- } \\
\text { scale }^{\mathrm{a}}\end{array}$} & 3.88 & 1.40 & 1.34 & 0.98 & 3.01 & 1.57 & 1.34 & 0.75 & G & 30 & 35.41 & 0.00 & 0.54 & $\begin{array}{l}\mathrm{G} \\
\mathrm{T}\end{array}$ & $\begin{array}{l}30 \\
30\end{array}$ & $\begin{array}{r}29.29 \\
5.37\end{array}$ & $\begin{array}{l}0.00 \\
0.03\end{array}$ & $\begin{array}{l}0.49 \\
0.15\end{array}$ \\
\hline & & & & & & & & & & & & & & $G_{x} T$ & 30 & 5.37 & 0.03 & 0.15 \\
\hline \multirow{3}{*}{$\begin{array}{l}\text { D sub- } \\
\text { scale }^{a}\end{array}$} & 2.30 & 1.55 & 0.70 & 0.55 & 2.22 & 1.38 & 0.77 & 0.66 & G & 30 & 14.99 & 0.00 & 0.33 & $G$ & 30 & 16.26 & 0.00 & 0.35 \\
\hline & & & & & & & & & & & & & & $\mathrm{T}$ & 30 & 0.00 & 0.95 & 0.00 \\
\hline & & & & & & & & & & & & & & $G \times T$ & 30 & 0.34 & 0.57 & 0.01 \\
\hline \multirow{3}{*}{$\begin{array}{l}\text { PA sub- } \\
\text { scale }^{\text {a }}\end{array}$} & 4.03 & 0.93 & 4.69 & 0.96 & 4.05 & 0.80 & 4.47 & 0.98 & G & 30 & 3.88 & 0.06 & 0.11 & $G$ & 30 & 3.19 & 0.08 & 0.10 \\
\hline & & & & & & & & & & & & & & $\mathrm{T}$ & 30 & 0.62 & 0.44 & 0.02 \\
\hline & & & & & & & & & & & & & & $G_{x} T$ & 30 & 0.91 & 0.35 & 0.03 \\
\hline \multirow{3}{*}{$\begin{array}{l}\text { SCL-90 } \\
-\mathrm{R}^{\mathrm{a}}\end{array}$} & 173.75 & 41.98 & 114.00 & 21.01 & 135.60 & 37.75 & 106.69 & 14.12 & G & 30 & 26.56 & 0.00 & 0.47 & G & 29 & 20.94 & 0.00 & 0.42 \\
\hline & & & & & & & & & & & & & & $\mathrm{T}$ & 29 & 15.15 & 0.00 & 0.34 \\
\hline & & & & & & & & & & & & & & $G \times T$ & 29 & 6.67 & 0.02 & 0.19 \\
\hline \multirow[t]{3}{*}{$\mathrm{CFQ}^{\mathrm{a}}$} & 48.63 & 17.52 & 30.06 & 9.81 & 38.44 & 15.72 & 27.94 & 12.13 & G & 30 & 13.67 & 0.00 & 0.31 & $G$ & 30 & 9.57 & 0.00 & 0.24 \\
\hline & & & & & & & & & & & & & & $\mathrm{T}$ & 30 & 13.29 & 0.00 & 0.31 \\
\hline & & & & & & & & & & & & & & $G \times T$ & 30 & 5.70 & 0.02 & 0.16 \\
\hline \multirow{3}{*}{$\begin{array}{l}\text { 2-Back } \\
\text { Task }{ }^{\mathrm{b}}\end{array}$} & 34.50 & 15.28 & 43.94 & 7.59 & 40.19 & 12.40 & 46.94 & 8.53 & G & 30 & 4.90 & 0.04 & 0.14 & $\mathrm{G}$ & 30 & 4.71 & 0.04 & 0.14 \\
\hline & & & & & & & & & & & & & & $\mathrm{T}$ & 30 & 8.33 & 0.01 & 0.22 \\
\hline & & & & & & & & & & & & & & $G \times T$ & 30 & 0.80 & 0.38 & 0.03 \\
\hline \multirow[t]{3}{*}{ SART c } & 10.00 & 4.15 & 9.94 & 5.09 & 6.75 & 4.63 & 7.00 & 5.56 & G & 30 & 0.00 & 0.97 & 0.00 & $G$ & 30 & 0.00 & 0.95 & 0.00 \\
\hline & & & & & & & & & & & & & & $\mathrm{T}$ & 30 & 19.31 & 0.00 & 0.39 \\
\hline & & & & & & & & & & & & & & $G \times T$ & 30 & 0.05 & 0.83 & 0.00 \\
\hline $\begin{array}{l}\text { Matching } \\
\text { Task }\end{array}$ & & & & & & & & & Rt & 30 & 37.59 & 0.00 & 0.56 & Rt & 30 & 62.20 & 0.00 & 0.68 \\
\hline $\begin{array}{l}\text { RT } \\
\text { switch }^{d}\end{array}$ & 1236 & 251.59 & 1015 & 190.52 & 1109 & 222.15 & 947 & 153.72 & G & 30 & 9.69 & 0.00 & 0.24 & G & 30 & 8.86 & 0.01 & 0.23 \\
\hline RT rep- & 1073 & 195.71 & 889 & 126.14 & 993 & 231.22 & 834 & 138.62 & $\mathrm{Rt} \times \mathrm{G}$ & 30 & 0.60 & 0.45 & 0.02 & $\mathrm{~T}$ & 30 & 14.88 & 0.00 & 0.33 \\
\hline etition ${ }^{d}$ & & & & & & & & & & & & & & $R t \times G$ & 30 & 0.36 & 0.55 & 0.01 \\
\hline & & & & & & & & & & & & & & $R t \times T$ & 30 & 1.01 & 0.32 & 0.03 \\
\hline & & & & & & & & & & & & & & $G \times T$ & 30 & 0.97 & 0.33 & 0.03 \\
\hline & & & & & & & & & & & & & & $R t \times G \times T$ & 30 & 0.33 & 0.57 & 0.01 \\
\hline
\end{tabular}

a Total score.

${ }^{\mathrm{b}}$ Correct responses.

c Inhibition errors.

${ }^{\mathrm{d}}$ Reaction times in milliseconds.

performance of both groups significantly improved over time. The latter result was probably due to a learning effect. The absence of an interaction effect indicated that the difference between the groups did not significantly differ before compared to after the 10-week period.

With regard to the number of inhibition errors in the SART, we found that neither the main effect of group nor the group $\times$ time interaction were significant. Thus, there was no evidence that the burnout group performed worse than the control group. Similarly to the 2-Back Task, we found a main effect of time, reflecting better performance on the second compared to the first test session, which was presumably caused by a learning effect.

Analysis of the reaction times of the first trial of each task run in the Matching Task revealed significant main effects of run type, group, and time, but none of the interactions were significant. The main effect of run type indicated that, overall, the average reaction times of both groups was significantly slower on switch than repetition trials. The main effect of group reflected that, overall and irrespective of run type, individuals with burnout were significantly slower compared to healthy individuals. Importantly, however, this difference was further qualified neither by an interaction between run type and group nor an interaction between run type, group, and time. The main effect of time revealed that independent of run type, the average reaction time of both groups was significantly faster on the second than on the first measurement. In line with the improved performance on the SART and the 2-Back Task, this was 
probably due to a learning effect. Yet, the main effect of time was not further qualified by a group $\times$ time interaction.

In sum, although the performance of both groups improved from the first to the second session, which was probably due to a learning effect, the 10 -week period with CBT did not yield clear positive effects on cognitive test performance of the burnout individuals.

\section{Discussion}

The aim of this study was twofold. First, we aimed to examine whether burnout is associated with self-reported cognitive difficulties and deficits in executive functioning, as measured with tests that assess the executive functions updating, inhibition, and switching. Second, we wanted to test whether these potential self-reported cognitive difficulties and deficits in executive functioning in burnout diminish after a 10 -week period of CBT.

\section{Burnout and cognitive functioning}

Regarding our first aim, we found that, on the first measurement, individuals with burnout reported considerably more cognitive failures than healthy individuals. This finding is consistent with the results of several previous studies on burnout $(15,16,21)$ and with numerous clinical observations. Interestingly, burnout was also associated with impaired performance on two of the three cognitive tests (the 2-Back and the Matching tasks). This implicates that the self-reported cognitive complaints in burnout can be substantiated with objective difficulties in cognitive performance. Whether or not such difficulties resulted from specific deficits in executive functioning or, instead, indicate a more general cognitive decline is less clear. More specifically, the individuals with burnout showed performance deficits on the 2-Back Task, which indicates that they had problems with the updating executive function. However, even though employees with burnout underperformed compared to healthy individuals on the Matching Task, the pattern of deficits seems to indicate a more general cognitive decline, that is, an overall reaction time increase instead of specific problems with the transition from repetition to switch trials. Thus, switch costs were not significantly longer for individuals in the burnout group, suggesting that the corresponding and specific executive function (switching) was not impaired. Furthermore, the burnout group did not perform significantly worse than the healthy controls on the SART, indicating that they were still able to inhibit responses adequately.

Our finding that, compared to healthy individuals, individuals with burnout generally reacted slower on the Matching Task is in line with results in previous stud- ies (15-20), in which burnout was found to be related with performance deficits in complex speed measures. The result that, compared to the healthy controls, the burnout group underperformed on the working memory task (updating and monitoring of working memory representations) is also consistent with findings in previous studies $(15,17)$, wherein burnout was associated with impairments in working memory processes. However, our findings that individuals with burnout did not perform worse than healthy individuals on the inhibition and switching tests, is in contrast to the findings of previous studies, in which evidence for differences in inhibition (20) and switching (15) was obtained. These inconsistent results might be related to differences in burnout samples between the studies. In the present study we explicitly examined burnout patients without a mood or anxiety disorder, whereas the other studies assessed a more heterogeneous sample in this respect. However, to date, the question concerning the generality or specificity of cognitive deficits (ie, general cognitive decline and/or impairments in specific executive functions) in burnout cannot be conclusively answered yet.

\section{Changes after a 10-week period with cognitive behavioral therapy}

As to our second aim, we found that the level of emotional exhaustion (Utrechtse Burnout Scale) and the number of physical and mental complaints (SCL-90-R) of individuals with burnout significantly and substantially decreased after a 10 -week period of CBT. This suggests that the treatment had a positive effect on subjective burnout symptoms as well as on general health complaints. Note that as we did not have a wait-list control group (a group of individuals with burnout that did not receive treatment), we cannot conclusively answer the question whether the improvement was really due to the treatment or was (also) an effect of the lapse of time and/or the fact that some individuals with burnout were on sick leave or worked only part-time. However, for our purposes, this was not crucial. The main focus of this study was whether or not the expected reduction in burnout symptoms and more general physical and mental complaints were accompanied by a decline in both subjective and objective cognitive performance. The results of this study confirmed this partially: the self-reported cognitive performance of individuals with burnout improved during the 10-week period with CBT. However, although the cognitive test performance of both the burnout and the control group improved probably due to a general learning effect, we found no direct evidence that the differences in cognitive test performance (ie, number of correct responses in the 2-back task and general reaction times in the Matching Task) between both groups had decreased after the 10-week 
period. Hence, whatever recovery processes took place during the 10 -week period with CBT regarding the subjective complaints, we found no proof that the objective cognitive performance of the burned out employees improved during that time.

There are several possible explanations for why individuals with burnout still underperformed on the cognitive tests compared to healthy individuals on the second measurement. One possibility is that the high levels of stress, which are associated with burnout, lead to permanent brain changes among individuals with burnout and that these changes are mediated by enhanced glucocorticoid levels as outlined in the introduction. However, whether glucocorticoids indeed play a role in cognitive effects in burnout is currently difficult to establish as the results of studies in this research field are mixed. For example, studies reported reduced $(16,17)$, equal $(42,43)$, and elevated $(44,45)$ cortisol levels among individuals with burnout compared to healthy individuals. Clearly, more insight into potential (neuro)endocrine abnormalities among individuals with burnout, and the possible effects of these abnormalities upon cognition and the brain, is required. Therefore, future longitudinal studies spanning longer time intervals might test individuals with burnout by comparing them to matched healthy individuals on both cognitive performance and (neuro)endocrine-system functioning. In addition, neuroimaging techniques could be used to examine whether brain regions involved in important cognitive processes, such as the (dorsolateral) prefrontal cortex and the hippocampus, of individuals with burnout deviate from those of healthy individuals.

A second explanation is that the amount of treatment sessions and/or the time interval between the first and the second measurement was simply not sufficient to bring about major changes in cognitive functioning. Although we found supportive evidence pointing to a significant decrease of burnout symptoms and general health complaints in the burnout group, the level of symptoms and complaints were still high compared to norm scores and still significantly higher than those of the control group. In addition, it should be kept in mind that treatment of the individuals with burnout had not ended at the time of the second measurement. Thus, the burnout group had "become better, but not well yet". Accordingly, we cannot rule out the possibility that after a longer period of continued CBT (ie, more sessions) burnout symptoms and general health complaints would have decreased further and/or self-reported cognitive functioning and cognitive test performance would have improved further. Hence, future studies should preferably include more than one follow-up measurement and follow individuals with burnout over a longer period of time.

A third explanation is that individuals in the burnout group had already experienced cognitive deficits before they developed a burnout. Since executive functions are considered to be essential in coping effectively with stress $(46,47)$, impairments in executive functioning might, at least theoretically, play an important role in the development of burnout. Accordingly, when confronted with stressors on the job, executive dysfunction might lead to inadequate coping strategies that may enhance the probability of developing a burnout. Unfortunately, to the authors' knowledge there are no studies yet that have investigated whether impairments in executive (and/or general cognitive) functioning precede burnout.

\section{Strengths and limitations}

An asset of this study was that the participants in the burnout group were selected on the basis of a highquality burnout diagnosis, as established by professional clinical psychologists. Moreover, we only selected participants for the burnout group without comorbid disorders. In many previous studies, participants in the burnout group consisted of a mix of individuals that may have had a comorbid disorder (eg, a mood and/or anxiety disorder) in addition to their burnout diagnosis. A burnout sample without comorbid disorders enabled us to carry out a relatively "pure" assessment of the relationship between burnout and cognition.

Another strength is that we systematically examined executive functioning. In previous studies, a variety of executive functions were assessed with various cognitive neuropsychological tests. In this study, however, we closely followed the literature and focused on three well-documented and basic types of executive functions that we assessed with well-validated tests, each tapping specifically into one of the three target functions.

This study also has its limitations. Firstly, it is hard to make clear causal inferences from the present data. We treated cognitive functioning as an outcome variable influenced by burnout. Our findings that burnout was associated with cognitive deficits, however, do not rule out the possibility of a reverse causal relation, nor of a bi-directional relationship. In other words, cognitive deficits may be both cause and consequence of burnout. Studies with more repeated measurements may shed more light on the issue of causality in the relationship between burnout and cognitive functioning.

Furthermore, we did not include a wait-list control group. Such a group would have enabled us to assess whether the changes that were observed in the present burnout group were due to the treatment, the lapse of time, or both. Clearly, this study on possible dynamic changes in cognitive performance of burnout individuals must be supplemented by further research.

Another limitation is that some of the individuals with burnout already had received one or two therapy sessions before their first testing session, which may 
have decreased the chance of finding a therapy effect. However, it is not very likely that this influenced the study outcomes, since these first two therapy sessions consisted mostly of psychoeducation and the registration of complaints.

As caffeine intake may affect cognitive performance (48), we asked participants not to consume any caffeine on both test sessions. One might argue that withholding participants from their daily caffeine intake may have had an effect on their cognitive performance as well. However, in that case, it seems implausible that caffeine deprivation would have had a different impact in both groups.

Finally, the sample size in our study, though carefully selected and matched, was of a relatively small size. However, despite the limited sample size, we found several meaningful statistically significant differences between the two groups, while at the same time, the large majority of the major null results clearly were not due to a lack of statistical power (given the high P-values and low $\eta^{2}$-values associated with the corresponding analyses). Nevertheless, future studies might preferably use larger study samples and more repeated measurements to examine burnout and cognitive functioning in relation to treatment and time lapse.

\section{Concluding remarks}

Although we found that burnout was associated with self-reported cognitive difficulties, relatively slow responding, and impaired executive functioning, we did not find evidence that burnout was associated with deficits in all executive functions that we assessed. Based on the present results, combined with the results of previous studies on the relationship between burnout and cognitive functioning, we therefore conclude that the specific nature of cognitive decline in burnout is not clear yet.

While evidence was obtained that a 10 -week period containing CBT "brought about" positive changes in burnout symptoms and general health complaints, individuals with burnout only showed improvements with respect to self-reported cognitive functioning. No evidence was found that individuals with burnout improved regarding their cognitive test performance. Until further research provides conclusive evidence, multiple explanations can be given for this result.

\section{Acknowledgments}

We would like to express our gratitude to Dr Edita Poljac and Hubert Voogd, MSc, for their technical assistance and the personnel of HSK Group and Eva van Rooij, MSc, for her support in data acquisition. Finally and above all, we wish to thank all participants who took part in this study.

\section{References}

1. Packham C, Webster S. Psychosocial working conditions in Britain in 2009. London: Health and Safety Executive; 2009.

2. Parent-Thirion A, Fernández Macías E, Hurley J, Vermeylen G. Fourth European working conditions survey. Luxembourg: Office for Official Publications of the European Communities; 2007.

3. Donald I, Taylor P, Johnson S, Cooper C, Cartwright S, Robertson S. Work environments, stress, and productivity: An examination using ASSET. Int J Stress Manage. 2005;12:409 23. http://dx.doi.org/10.1037/1072-5245.12.4.409.

4. Moreau M, Valente F, Mak R, Pelfrene E, de Smet P, De Backer $\mathrm{G}$, et al. Occupational stress and incidence of sick leave in the Belgian workforce: The Belstress study. J Epidemiol Commun H. 2004;58:507-16. http://dx.doi.org/10.1136/ jech.2003.007518.

5. Cordes CL, Dougherty TW. A review and an integration of research on job burnout. Acad Manage Rev. 1993;18:621-56.

6. Maslach C, Schaufeli WB, Leiter MP. Job burnout. Annu Rev Psychol. 2001;52:397-422. http://dx.doi.org/10.1146/ annurev.psych.52.1.397.

7. Schaufeli WB, Enzmann D. The burnout companion to study and practice: A critical analysis. London: Taylor \& Francis; 1998.

8. American Psychiatric Association. Diagnostic and statistical manual of mental disorders. 4th ed. Washington, DC: American Psychiatric Association; 2000.

9. Toker S, Shirom A, Shapira I, Berliner S, Melamed S. The association between burnout, depression, anxiety, and inflammation biomarkers: C-reactive protein and fibrinogen in men and women. J Occup Health Psych. 2005;10:344-62. http://dx.doi.org/10.1037/1076-8998.10.4.344.

10. Arnsten AFT. Stress signaling pathways that impair prefrontal cortex structure and function. Nat Rev Neurosci. 2009;10:410 22. http://dx.doi.org/10.1038/nrn2648.

11. Lupien SJ, Lepage M. Stress, memory, and the hippocampus: Can't live with it, can't live without it. Behav Brain Res. 2001;127:137-58. http://dx.doi.org/10.1016/S01664328(01)00361-8.

12. McEwen BS. Glucocorticoids, depression, and mood disorders: Structural remodeling in the brain. Metabolism. 2005;54:20-3. http://dx.doi.org/10.1016/j.metabol.2005.01.008

13. Coburn-Litvak PS, Tata DA, Gorby HE, McCloskey DP, Richardson G, Anderson BJ. Chronic corticosterone affects brain weight, and mitochondrial, but not glial volume fraction in hippocampal area CA3. Neuroscience. 2004;124:429-38. http://dx.doi.org/10.1016/j.neuroscience.2003.11.031.

14. McEwen BS. Protective and damaging effects of stress mediators. New Engl J Med. 1998;338:171-9. http://dx.doi. 
org/10.1056/NEJM199801153380307.

15. Öhman L, Nordin S, Bergdahl J, Birgander LS, Neely AS. Cognitive function in outpatients with perceived chronic stress. Scand J Work Environ Health. 2007;33:223-32.

16. Österberg K, Karlson B, Hansen ÅM. Cognitive performance in patients with burnout, in relation to diurnal salivary cortisol. Stress. 2009;12:70-81. http://dx.doi. org/10.1080/10253890802049699.

17. Rydmark I, Wahlberg K, Ghatan PH, Modell S, Nygren A, Ingvar $\mathrm{M}$, et al. Neuroendocrine, cognitive and structural imaging characteristics of women on longterm sickleave with job stress-induced depression. Biol Psychiat. 2006;60:867-73. http://dx.doi.org/10.1016/j.biopsych.2006.04.029.

18. Sandström A, Peterson J, Sandström E, Lundberg M, Nystrom IL, Nyberg L, Olsson T. Cognitive deficits in relation to personality type and hypothalamic-pituitary-adrenal (HPA) axis dysfunction in women with stress-related exhaustion. Scand J Psychol. 2011;52:71-82. http://dx.doi.org/10.1111/ j.1467-9450.2010.00844.x.

19. Sandström A, Rhodin IN, Lundberg M, Olsson T, Nyberg L. Impaired cognitive performance in patients with chronic burnout syndrome. Biol Psychol. 2005;69:271-9. http:// dx.doi.org/10.1016/j.biopsycho.2004.08.003.

20. Van der Linden D, Keijsers GPJ, Eling P, Van Schaijk R. Work stress and attentional difficulties: An initial study on burnout and cognitive failures. Work Stress. 2005;19:23-36. http:// dx.doi.org/10.1080/02678370500065275.

21. Wahlberg K, Ghatan PH, Modell S, Nygren A, Ingvar M, Asberg M, Heilig M. Suppressed neuroendocrine stress response in depressed women on job-stress-related longterm sick leave: A stable marker potentially suggestive of preexisting vulnerability. Biol Psychiat. 2009;65:742-7. http:// dx.doi.org/10.1016/j.biopsych.2008.10.035.

22. Miyake A, Friedman NP, Emerson MJ, Witzki AH, Howerter A, Wager TD. The unity and diversity of executive functions and their contributions to complex "frontal lobe" tasks: A latent variable analysis. Cognitive Psychol. 2000;41:49-100. http:// dx.doi.org/10.1006/cogp.1999.0734.

23 D'Esposito M, Detre JA, Alsop DC, Shin RK, Atlas S, Grossman M. The neural basis of the central executive system of working memory. Nature. 1995;378:279-81.

24. Miller EK, Cohen JD. An integrative theory of prefrontal cortex function. Annu Rev Neurosci. 2001;24:167-202. http:// dx.doi.org/10.1146/annurev.neuro.24.1.167.

25. Norman DA, Shallice T. Attention to action: Willed and automatic control of behavior. In Davidson RJ, Schwartz GE, Shapiro D editors. Consciousness and self-regulation: Advances in research and theory, vol. 4. New York: Plenum Press; 1986, p. 1-18.

26. Chan RCK, Shum D, Toulopoulou T, Chen EYH. Assessment of executive functions: Review of instruments and identification of critical issues. Arch Clin Neuropsych. 2008;23:201-16. http://dx.doi.org/10.1016/j.acn.2007.08.010.

27. Keijsers GPJ, Vossen CJC, Schaap CPDR, Boelaars V, Van Minnen A, Hoogduin CAL. Protocollaire behandeling van patiënten met burnout: Modulaire behandeling [Manualized treatment of patients with burnout: Modular treatment]. In Keijsers GPJ, Van Minnen A, Hoogduin CAL editors. Protocollaire behandelingen in de ambulante geestelijke gezondheidszorg II. Houten, the Netherlands: Bohn Stafleu Van Loghum; 2004, p. 205-80. http://dx.doi.org/10.1007/978-90313-7117-4.

28. Ahola K, Honkonen T, Isometsä E, Kalimo R, Nykyri, E, Aromaa A, Lönnqvist J. The relationship between job-related burnout and depressive disorders: Results from the Finnish Health 2000 Study. J Affect Disorders. 2005;88:55-62. http:// dx.doi.org/10.1016/j.jad.2005.06.004.

29. Overbeek T, Schruers K, Griez E. MINI. Mini International Neuropsychiatric Interview. Dutch version 5.0.0. DSM-IV. Maastricht, the Netherlands: University of Maastricht; 1999.

30. Sheehan DV, Lecrubier Y, Sheehan KH, Amorim P, Janavs J, Weiller E, et al. The Mini-International Neuropsychiatric Interview (MINI): The development and validation of a structured diagnostic psychiatric interview for DSM-IV and ICD-10. J Clin Psychiat. 1998;59:22-33.

31. Schaufeli WB, Van Dierendonck D. UBOS. Utrechtse Burnout Schaal Handleiding [Utrechtse Burnout Scale Handbook]. Lisse, the Netherlands: Swets \& Zeitlinger; 2000.

32. Maslach C, Jackson SE, Leiter MP. Maslach Burnout Inventory. 3rd ed. Palo Alto, CA: Consulting Psychologists Press; 1996.

33. Brenninkmeijer V, Van Yperen N. How to conduct research on burnout: Advantages and disadvantages of a unidimensional approach in burnout research. Occup Environ Med. 2003;60:1620. http://dx.doi.org/10.1136/oem.60.suppl_1.i16.

34. Arrindell WA, Ettema JHM. SCL-90. Handleiding bij een multidimensionele psychopathologie-indicator. Lisse, the Netherlands: Swets \& Zeitlinger; 2003.

35. Derogatis LR. SCL-90-R. Administration, scoring and procedures manual-I for the R(evised) version. Baltimore: Johns Hopkins University School of Medicine, Clinical Psychometrics Research Unit; 1977.

36. Broadbent DE, Cooper PF, Fitzgerald P, Parkes KR. The Cognitive Failures Questionnaire (CFQ) and its correlates. Brit J Clin Psychol 1982;21:1-16. http://dx.doi. org/10.1111/j.2044-8260.1982.tb01421.x.

37. Robertson IH, Manly T, Andrade J, Baddeley BT, Yiend J. 'Oops!': Performance correlates of everyday attentional failures in traumatic brain injured and normal subjects. Neuropsychologia. 1997;35:747-58. http://dx.doi. org/10.1016/S0028-3932(97)00015-8.

38. Kirchner WK. Age differences in short-term retention of rapidly changing information. J Exp Psychol. 1958;55:352-8. http://dx.doi.org/10.1037/h0043688.

39. Poljac E, Simon S, Ringlever L, Kalcik D, Groen WB, Buitelaar JK, et al. Impaired task switching performance in children with dyslexia but not in children with autism. Q J Exp Psychol. 2010;63:401-16. http://dx.doi. org/10.1080/17470210902990803.

40. Jersild AT. Mental set and shift. Arch Psychol. 1927; 89: 1-82 41. Monsell S. Task switching. Trends Cogn Sci. 2003;7:134-40. 
http://dx.doi.org/10.1016/S1364-6613(03)00028-7.

42. Grossi G, Perski A, Evengård B, Blomkvist V, Orth-Gomér K. Physiological correlates of burnout among women. J Psychosom Res. 2003;55:309-16. http://dx.doi.org/10.1016/ S0022-3999(02)00633-5.

43. Mommersteeg PMC, Heijnen CJ, Verbraak MJPM, Van Doornen LJP. Clinical burnout is not reflected in the cortisol awakening response, the day-curve or the response to a low-dose dexamethasone suppression test. Psychoneuroendocrino. 2006;31:216-25. http://dx.doi. org/10.1016/j.psyneuen.2005.07.003.

44. De Vente W, Olff M, Van Amsterdam JGC, Kamphuis JH, Emmelkamp PMG. Physiological differences between burnout patients and healthy controls: Blood pressure, heart rate, and cortisol responses. Occup Environ Med. 2003;60:54-61. http://dx.doi.org/10.1136/oem.60.suppl_1.i54.
45. Grossi G, Perski A, Ekstedt M, Johansson T, Lindström M, Holm K. The morning salivary cortisol response in burnout. J Psychosom Res. 2005;59:103-11. http://dx.doi.org/10.1016/j. jpsychores.2005.02.009.

46. Declerck CH, Boone C, De Brabander B. On feeling in control: A biological theory for individual differences in control perception. Brain Cognition. 2006;62:143-76. http://dx.doi. org/10.1016/j.bandc.2006.04.004.

47. Williams PG, Suchy Y, Rau HK. Individual differences in executive functioning: Implications for stress regulation. Ann Behav Med. 2009;37:126-40. http://dx.doi.org/10.1007/ s12160-009-9100-0.

48. Glade MJ. Caffeine-Not just a stimulant. Nutrition. 2010;26:932-8. http://dx.doi.org/10.1016/j.nut.2010.08.004

Received for publication: 8 May 2011 